\title{
An Empirical Study on Current Stress and Physical Exercise Among University Students: A Case Study of Several Universities in Beijing
}

\author{
Moyan Li ${ }^{1, *}$, Pengyu Deng ${ }^{2}$ \\ ${ }^{1}$ School of Physical Education (Physical Education Teachers College), Beijing Sport University, Beijing 100084, China \\ ${ }^{2}$ Sports Business School, Beijing Sport University, Beijing 100084, China
}

\begin{abstract}
Objective: To investigate the current stress and physical activity situations of college students and analyze the reasons for them, so as to provide suggestions for further promoting college students' mental health and physical activity. Methods: Using the questionnaire survey method, 221 cases of students enrolled in four universities in Beijing were selected to be measured on the Stress Scale, Physical Activity Rating Scale and situation scale for university students. Results: Some of the students in the Beijing universities currently surveyed are at an ordinary level of stress and have a moderate physical activity level. Stress from academic annoyances was highest, with 17.6 per cent of students in a high stress state. There is a degree of difference in stress and physical activity between male and female students, academic and sports students, second year students and students in other grades. There was a highly significant negative correlation between physical activity and the personal annoyance and study annoyance dimensions. Students' personal annoyance and academic annoyance can predict physical activity to some extent. Conclusion: Stress has an important impact on the mental health and development of university students. At present, the mental health of university students should first focus on their academic stress, and pay attention to the stress of different grades and male and female students separately. It is also important to give full play to the role of physical exercise in regulating stress.
\end{abstract}

Keywords: University students, Stress, Physical exercise, Mental health education.

\section{Introduction}

In 1948 the World Health Organization Charter stated that health is not only the absence of disease or infirmity, but also a state of complete physical, mental and social well-being[1-2]. And mental health is closely related to stress, and some scholars point out that stress is one of the most important factors affecting mental health[3-5]. The Dictionary of Social Psychology, edited by Shi Ronghua, points out that stress is a psychological experience that occurs when an individual's conventional methods of dealing with a threat fail, and that when the subject and object interact, the routine to which the individual is accustomed cannot be continued due to new stimuli, which in turn generates stress[6].

At present, due to the increasingly fierce competition in society, the pressure on university students is increasing and there are phenomena of some students being unable to cope with some of the pressure and having adverse physical and mental consequences[7-8]. The ability to cope well with stress is generally considered to be explored from both internal and external aspects. If individuals have a personality or internal temperament such as self-confidence and optimism, it is conducive to self-adjustment and overcoming when faced with stress. For example, studies by scholars such as Bovier found that having sufficient internal resources, such as self-control and self-esteem, may be an important prerequisite for young people's psychological well-being[9]. On the external side, having good external factors such as acceptance of failure and education about overcoming stress and coping with stress can also be beneficial in facilitating students to address the problems caused by stress, for example, research by scholars such as Joelle C. Ruthig noted that social support predicted less stress[10].
Appropriate physical exercise can help to relieve stress better[11-12]. The impact of physical exercise on stress includes both internal and external aspects, in the internal aspect physical exercise can enhance the ability to resist stress[13-14]; in the external aspect physical exercise places can provide a cathartic platform to relieve stress. However, most studies on the effects of physical exercise on mental health have focused on the effects on depression and anxiety, but less on the effects of stress. This study investigates the effects of stress and physical exercise on students in some universities in Beijing to explore the effects of physical exercise on stress, with a view to providing suggestions for better promoting the development of psychological health and strengthening physical exercise among university students.

\section{Methodology}

\subsection{Participants}

This study used an online anonymous survey, which was conducted among students enrolled in four universities in Beijing. 250 questionnaires were sent out on 15 January 2022, and 221 valid questionnaires were returned, with an effective rate of $88.4 \%$. General demographic information, stress status, and physical activity were collected.

\subsection{Measures}

\subsubsection{Self-compiled general information questionnaire}

General demographic information is collected on gender, grade, student category, school, as well as information related to daily exercise, including attitudes, motivation, time, frequency, sport and factors that hinder exercise participation. 


\subsubsection{Physical Activity Rating Scale}

The Chinese version of The Physical Activity Rating Scale-3 (PARS-3) was revised by scholar Liang Deqing et al. It has good reliability and validity[15] and can better analyse the amount of physical activity among university students. There are 3 entries in total, where exercise intensity is scored from 1 to 5 , exercise frequency is scored from 1 to 5 , exercise duration is scored from 0 to 4 , and exercise volume is the multiplication of the three entries. The score of 19 points and below is a small amount of exercise (insufficient amount of exercise), 20-42 is divided into a moderate amount of exercise, 43 points and above is a large amount of exercise. The Cronbach alpha coefficient for this scale in this study survey was 0.788 .

\subsubsection{Stress Questionnaire for University Students}

The Stress Scale for College Students, developed by scholars Li Hong and Mei Jinrong, was used as the basic questionnaire for stress among college students. The scale has good reliability and validity and is widely used to analyse the stress situation of college students. The questionnaire consists of 30 items and is scored on a four-point scale, with no stress being scored as 0 , mild stress as 1 , moderate stress as 2 and severe stress as 3. A total score above 45 is considered high stress[16].

For the reliability test, the Cronbach alpha coefficients of the total scale and each dimension were calculated separately.
According to the results, the Cronbach alpha coefficients for each dimension ranged from 0.917 to 0.964 , and the Cronbach alpha coefficient for the total scale was 0.972 . Therefore, the questionnaire used in this study has a high degree of internal consistency in reliability.

In terms of validity testing, this study was tested for structural validity through exploratory factor analysis. The Bartlett's spherical test showed a KMO value of $0.955, x^{2}=6408.390$, $\mathrm{df}=406, \mathrm{p}<0.001$, indicating that the data were suitable for exploratory factor analysis, which is shown in Table 1.

Table 1: Results of the KMO and Bartlett's tests of the stress questionnaire for university students

\begin{tabular}{ccc}
\hline $\begin{array}{c}\text { Kaiser-Meyer-Olkin Measure } \\
\text { of Sampling Adequacy }\end{array}$ & 0.955 \\
\hline & Approx. Chi-Square & 6408.39 \\
Bartlett's Test of Sphericity & df & 406 \\
& Sig. & 0 \\
\hline
\end{tabular}

Using principal component analysis to extract common factor variables. Determine the number of factors based on characteristic roots greater than 1. The item "personal annoyance13" was eliminated and the "negative life events" dimension was divided into two dimensions: "negative learning events" and "negative life events". The final College Student Pressure Questionnaire with 4 factors and 29 topics was formed, with a cumulative contribution rate of $74.117 \%$, which is shown in Table 2. A total score above 43.5 is therefore considered to be in a high stress state.

Table 2: Exploratory Factor Analysis of the Stress Scale for University Students

\begin{tabular}{|c|c|c|c|c|}
\hline Title & Personal Annoyance & Study Annoyance & Negative Learning Events & Negative Life Events \\
\hline Personal Annoyance 8 & 0.783 & & & \\
\hline Personal Annoyance9 & 0.767 & & & \\
\hline Personal Annoyance15 & 0.767 & & & \\
\hline Personal Annoyance 2 & 0.767 & & & \\
\hline Personal Annoyance 16 & 0.765 & & & \\
\hline Personal Annoyance12 & 0.762 & & & \\
\hline Personal Annoyance 3 & 0.762 & & & \\
\hline Personal Annoyance 14 & 0.757 & & & \\
\hline Personal Annoyance 6 & 0.754 & & & \\
\hline Personal Annoyance11 & 0.732 & & & \\
\hline Personal Annoyance 1 & 0.713 & & & \\
\hline Personal Annoyance 7 & 0.669 & & & \\
\hline Personal Annoyance 5 & 0.668 & & & \\
\hline Personal Annoyance 4 & 0.663 & 0.417 & & \\
\hline Personal Annoyance 10 & 0.617 & & & \\
\hline Study Annoyance 2 & & 0.788 & & \\
\hline Study Annoyance 4 & & 0.785 & & \\
\hline Study Annoyance 8 & & 0.778 & & \\
\hline Study Annoyance 6 & & 0.777 & & \\
\hline Study Annoyance 9 & & 0.760 & & \\
\hline Study Annoyance 7 & & 0.755 & & \\
\hline Study Annoyance 1 & & 0.755 & & \\
\hline Study Annoyance 3 & & 0.736 & & \\
\hline Study Annoyance 5 & & 0.729 & & \\
\hline Study Annoyance 10 & & 0.729 & & \\
\hline Negative Learning Event 12 & & & 0.768 & \\
\hline Negative Learning Event 11 & & & 0.759 & \\
\hline Negative Life Event 14 & & & & 0.803 \\
\hline Negative Life Event 13 & & & & 0.800 \\
\hline Characteristic roots & 16.549 & 2.421 & 1.486 & 1.038 \\
\hline Contribution rate & 57.064 & 8.349 & 5.124 & 3.579 \\
\hline Cumulative contribution rate & 57.064 & 65.413 & 70.537 & 74.117 \\
\hline
\end{tabular}

2.3 Data Analysis

SPSS 22.0 software was used to analyse the data obtained. After excluding extreme values or irrelevant data of the respondents according to the purpose of the study, t-test was used to analyse the differences between the total scores of the scale and the national norm; correlation analysis, regression analysis and ANOVA were used to explore the relationship 
between physical activity status and stress status and its relationship with each other.

\section{Results}

\subsection{General Characteristics of the Participants}

A total of 221 student questionnaires are valid, of which 102 $(46.15 \%)$ were male and $119(53.85 \%)$ were female; the grades were $60(27.15 \%)$ for first-year university students, 73 (33.03\%) for second-year university students, 52 (23.53\%) for third-year university students, $12(5.43 \%)$ for fourth-year university students, $24(10.86 \%)$ for master's and doctoral students; 147 (66.52\%) for subject students, 62 (28.05\%) for art students and $12(5.43 \%)$ for art students. 10.86\%); 147 $(66.52 \%)$ were academic students who focus on learning professional knowledge and skills; $62(28.05 \%)$ were sports students who focus on learning sports expertise and skills; and $12(5.43 \%)$ were art students, which is shown in Table 3.

Table 3: General characteristics of the participants $(\mathrm{N}=221)$

\begin{tabular}{cccc}
\hline & & $\mathrm{N}$ & Percentage (\%) \\
\hline \multirow{2}{*}{ Gender } & Male & 102 & 46.15 \\
& Women & 119 & 53.85 \\
& First year students & 60 & 27.15 \\
\multirow{4}{*}{ Grade Level } & Second year students & 73 & 33.03 \\
& Third year students & 52 & 23.53 \\
& Fourth year students & 12 & 5.43 \\
& Masters and PhD students & 24 & 10.86 \\
\multirow{3}{*}{ Student Category } & Academic Students & 147 & 66.52 \\
& Sports Students & 62 & 28.05 \\
& Art Students & 12 & 5.43 \\
\hline
\end{tabular}

3.2 Analysis of the Stress Situation of University Students
3.2.1 Basic description of stress in university students

Table 4 presents a descriptive statistical analysis of the stress profile of university students. Overall, the current survey of students' stress levels in four universities in Beijing was moderate. (26.733), with academic annoyances (1.062) being higher than personal annoyances (0.944) and higher than negative life events (0.602) and higher than negative academic events (0.378). The percentage of students in a high stress state (i.e. with an overall score above 43.5) was 17.6 per cent.

Table 4: Descriptive statistics of university students' stress profiles

\begin{tabular}{cccc}
\hline Dimensionality & N & Mean & Std.Deviation \\
\hline Study Annoyance & 221 & 1.062 & 0.748 \\
Personal Annoyance & 221 & 0.944 & 0.79 \\
Negative Life Events & 221 & 0.602 & 0.738 \\
Negative Learning Events & 221 & 0.378 & 0.604 \\
Total points & 221 & 26.733 & 19.741 \\
\hline
\end{tabular}

3.2.2 A comparison of stress profiles of university students by gender

An independent samples t-test analysis comparing the differences between male and female students' stress showed that there were extremely significant differences between male and female students on the personal annoyance dimension $(\mathrm{p}<0.001)$ and very significant differences on the negative learning events and total stress scores $(p<0.01)$, with male students having significantly higher personal annoyance, negative learning events and total stress scores than female students, which is shown in Table 5.

Table 5: Results of independent samples t-test for stress profiles of male and female students

\begin{tabular}{|c|c|c|c|c|c|c|c|}
\hline & Gender & $\mathrm{N}$ & Mean & Std. Deviation & $\mathrm{t}$ & Sig (2-tailed) & Cohen's d \\
\hline \multirow[t]{2}{*}{ Personal Annoyance } & Male & 102 & 1.203 & 0.984 & \multirow{2}{*}{4.516} & \multirow[t]{2}{*}{0.000} & \multirow[t]{2}{*}{0.623} \\
\hline & $\begin{array}{l}\text { Female } \\
\text { Male }\end{array}$ & $\begin{array}{l}119 \\
102\end{array}$ & $\begin{array}{l}0.721 \\
1.122\end{array}$ & 0.477 & & & \\
\hline Study Annoyance & Female & $\begin{array}{l}102 \\
119\end{array}$ & $\begin{array}{l}1.122 \\
1.011\end{array}$ & 0.623 & 1.070 & 0.286 & 0.147 \\
\hline \multirow{2}{*}{ Negative Learning Events } & Male & 102 & 0.505 & 0.666 & \multirow{2}{*}{2.894} & \multirow{2}{*}{0.004} & \multirow{2}{*}{0.394} \\
\hline & Female & 119 & 0.269 & 0.524 & & & \\
\hline \multirow{2}{*}{ Negative Life Events } & Male & 102 & 0.672 & 0.759 & \multirow{2}{*}{1.302} & \multirow{2}{*}{0.194} & \multirow{2}{*}{0.176} \\
\hline & Female & 119 & 0.542 & 0.718 & & & \\
\hline \multirow{2}{*}{ Total points } & Male & 102 & 31.618 & 24.098 & \multirow{2}{*}{3.357} & \multirow[t]{2}{*}{0.001} & \multirow{2}{*}{0.462} \\
\hline & Female & 119 & 22.546 & 13.830 & & & \\
\hline
\end{tabular}

3.2.3 A comparison of stress profiles of different categories of university students

In this study, students were categorised by academic, sports and art students, and only comparisons between subject and art students were made due to the limitations of the small number of art students. The differences between the two types were compared through independent sample t-test analysis.
The results of the study showed that there was an extremely significant difference between academic students and sports students on the academic annoyance and total stress score dimensions $(\mathrm{p}<0.001)$ and a highly significant difference on the personal annoyance dimension $(\mathrm{p}<0.01)$, with academic students having significantly higher total academic annoyance, personal annoyance and stress scores than sports students, as shown in Table 6.

Table 6: Results of independent sample t-tests for different categories of university students' stress profiles

\begin{tabular}{|c|c|c|c|c|c|c|c|}
\hline & Gender & $\mathrm{N}$ & Mean & Std. Deviation & $\mathrm{t}$ & Sig (2-tailed) & Cohen's d \\
\hline Personal Annoyance & $\begin{array}{l}\text { Academic Students } \\
\text { Sports Students }\end{array}$ & $\begin{array}{c}147 \\
62\end{array}$ & $\begin{array}{l}1.049 \\
0.726\end{array}$ & $\begin{array}{l}0.887 \\
0.496\end{array}$ & 3.345 & 0.001 & 0.449 \\
\hline Study Annoyance & $\begin{array}{l}\text { Academic Students } \\
\text { Sports Students }\end{array}$ & $\begin{array}{c}147 \\
62\end{array}$ & $\begin{array}{l}1.203 \\
0.771\end{array}$ & $\begin{array}{l}0.773 \\
0.625\end{array}$ & 3.891 & 0.000 & 0.615 \\
\hline Negative Learning Events & $\begin{array}{l}\text { Academic Students } \\
\text { Sports Students }\end{array}$ & $\begin{array}{c}147 \\
62\end{array}$ & $\begin{array}{l}0.435 \\
0.258\end{array}$ & $\begin{array}{l}0.628 \\
0.541\end{array}$ & 2.060 & 0.041 & 0.302 \\
\hline $\begin{array}{l}\text { Negative } \\
\text { Life Events }\end{array}$ & $\begin{array}{l}\text { Academic Students } \\
\text { Sports Students }\end{array}$ & $\begin{array}{l}147 \\
62\end{array}$ & $\begin{array}{l}0.653 \\
0.468\end{array}$ & $\begin{array}{l}0.753 \\
0.658\end{array}$ & 1.685 & 0.094 & 0.262 \\
\hline Total points & $\begin{array}{l}\text { Academic Students } \\
\text { Sports Students }\end{array}$ & $\begin{array}{c}147 \\
62\end{array}$ & $\begin{array}{l}29.932 \\
20.048\end{array}$ & $\begin{array}{l}21.356 \\
14.299\end{array}$ & 3.907 & 0.000 & 0.544 \\
\hline
\end{tabular}


3.2.4 A comparison of stress profiles of university students in different grades

In this study, students were divided into first year students, second year students, third year students, fourth year students, and master's and doctoral students. Due to the limitations of the current small number of fourth year students, only comparisons between other four categories were conducted. A one-way ANOVA comparing the differences between the four types reveals extremely significant variability in the personal annoyance, academic annoyance, and total score dimensions across the different year levels, as shown in Table 7 .

Table 7: Comparison of differences in stress profiles of university students by grade

\begin{tabular}{|c|c|c|c|c|c|c|}
\hline & $\begin{array}{c}\begin{array}{c}\text { First year students } \\
(\mathrm{n}=60) \\
(\text { Mean, SD) }\end{array} \\
\end{array}$ & $\begin{array}{c}\text { Second year students } \\
(\mathrm{n}=73) \\
(\text { Mean, SD) }\end{array}$ & $\begin{array}{c}\text { Third year students } \\
(\mathrm{n}=52) \\
(\text { Mean, SD) }\end{array}$ & $\begin{array}{c}\text { Masters and PhD } \\
\text { students (n=24) } \\
(\text { Mean, SD) }\end{array}$ & $\mathrm{F}$ & $\mathrm{p}$ \\
\hline Personal annoyance & $(0.736,0.500)$ & $(1.313,1.041)$ & $(0.794,0.573)$ & $(0.694,0.572)$ & 8.894 & 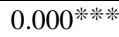 \\
\hline Study annoyance & $(0.870,0.636)$ & $(1.407,0.790)$ & $(0.967,0.653)$ & $(0.721,0.588)$ & 9.819 & 0.000 ***** \\
\hline $\begin{array}{l}\text { Negative learning } \\
\text { events }\end{array}$ & $(0.392,0.568)$ & $(0.514,0.702)$ & $(0.250,0.480)$ & $(0.208,0.487)$ & 7.306 & $0.043 *$ \\
\hline Negative life events & $(0.642,0.725)$ & $(0.699,0.789)$ & $(0.538,0.720)$ & $(0.417,0.620)$ & 8.689 & 0.348 \\
\hline Total points & $(21.800,14.776)$ & $(36.192,23.354)$ & $(23.154,15.950)$ & $(18.875,15.250)$ & 0.357 & 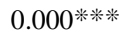 \\
\hline
\end{tabular}

Note: ${ }^{*} \mathrm{p}<0.05,{ }^{* * *} \mathrm{p}<0.01$, ***** $\mathrm{p}<0.001$.

Further multiple comparisons revealed that on the personal annoyance dimension, second year students were significantly higher than first year students $(\mathrm{p}<0.001)$ and second year students were significantly higher than third year students and master's and doctoral students $(\mathrm{p}<0.01)$, indicating that second year students were more stressed about personal annoyance than first year, third year students and master's and doctoral students. On the study annoyance dimension, second year students were significantly higher than first year students and doctoral students $(\mathrm{p}<0.001)$ and second year students were significantly higher than third year students $(p<0.01)$, indicating that second year students were more stressed about study annoyance than first year and third year students and master's and doctoral students. In terms of overall scores, second year students were significantly higher than first year students $(\mathrm{p}<0.001)$ and second year students were significantly higher than third year students and master's and doctoral students $(\mathrm{p}<0.01)$, indicating that the overall profile of stress was greater for second year students relative to first year and third year students and master's and doctoral students, as shown in Table 8.

Table 8: Multiple comparisons of students' stress profiles by grade level

\begin{tabular}{cccccc}
\hline Dependent variable & (I) Grade & (J) Grade & Mean Difference (I-J) & Std. Error & Sig. \\
\hline & & First year students & $0.578^{* * * * *}$ & 0.138 & 0.000 \\
Personal Annoyance & Second Year Students & Third year students & $0.520^{* * *}$ & 0.145 & 0.003 \\
& & Masters and PhD students & $0.619^{* * *}$ & 0.169 & 0.003 \\
& & First year students & $0.537^{* * * * *}$ & 0.121 & 0.000 \\
Study Annoyance & \multirow{2}{*}{ Second Year Students } & Third year students & $0.440^{* * *}$ & 0.126 & 0.001 \\
& & Masters and PhD students & $0.686^{* * * *}$ & 0.163 & 0.000 \\
Total points & & First year students & $14.392^{* * * *}$ & 3.333 & 0.000 \\
& \multirow{2}{*}{ Second Year Students } & Third year students & $13.038^{* * *}$ & 3.516 & 0.002 \\
& & Masters and PhD students & $17.317^{* * *}$ & 4.143 & 0.001 \\
\hline
\end{tabular}

Note: ${ }^{*} \mathrm{p}<0.05$, ** $\mathrm{p}<0.01$, ${ }^{*} * * \mathrm{p}<0.001$.

\subsection{Analysis of University Students' Physical Activity}

3.3.1 Basic description of university students' physical activity

Table 9: Descriptive statistics of university students' physical activity

\begin{tabular}{cccc}
\hline Dimensionality & $\mathrm{N}$ & Mean & Std.Deviation \\
\hline Exercise intensity & 221 & 2.7 & 1.356 \\
Exercise time & 221 & 2.7 & 1.255 \\
Number of workouts & 221 & 3.28 & 1.071 \\
Physical activity (total points) & 221 & 31.131 & 28.196 \\
\hline
\end{tabular}

Table 9 presents a descriptive statistical analysis of physical activity among university students. Overall, the physical activity level of some of the universities in Beijing surveyed was moderate (31.131), with a calculated physical activity level of moderate (21.796) for academic students and a level of heavy (53.355) for sports students. The results showed that the average intensity of exercise (2.700) ranged between less intense exercise of low intensity and more intense and sustained exercise of medium intensity, the average duration of exercise (2.700) ranged from "21 to 30 minutes" to " 31 to 59 minutes", and the average number of exercises (3.280) ranged from " 1 to 2 times per week" to " 3 to 5 times per week".

Table 10 shows the average composite score for the ranking question "Purpose of physical exercise for university students (only three items can be chosen)". The average composite score of the options $=(\Sigma$ frequency $\times$ weight $) /$ number of respondents), which reflects the composite ranking of the options, with higher scores indicating a higher composite ranking. The data shows that the main purposes of exercise among university students are to satisfy their personal interests (4.22), to keep fit (3.5) and to regulate psychological stress (3.25).

Table 10: Average composite score for the ranked question "Purpose of physical activity for university students (only three items can be chosen)"

\begin{tabular}{cc}
\hline Purpose of exercise & Average composite score \\
\hline Personal Interests & 4.22 \\
Staying in shape & 3.5 \\
Regulating psychological stress & 3.25 \\
Disease prevention & 1.13 \\
Other (mainly curriculum and school & 0.96 \\
requirements) & 0.87 \\
Social interaction & 0.22 \\
Keeping up with trends & \\
\hline
\end{tabular}


Table 11 shows the average composite score for the ranked question "Physical activity for university students (only three items can be chosen)". The data shows that the current exercise programs for university students are mainly running or brisk walking (10.67) and basketball (3.37). There is a wide range of sports to be tried by students.

Table 11: Average composite score for the ranked question

"Physical activity for students (only three items can be

\begin{tabular}{cc}
\multicolumn{2}{c}{ chosen)" } \\
\hline Physical activity & Average composite score \\
\hline Running or brisk walking & 10.67 \\
Other (including swimming, boxing, & 3.52 \\
badminton, etc.) & 3.37 \\
Basketball & 3.1 \\
Push-ups, sit-ups, plank support, etc. & 2.33 \\
Bicycles & 1.57 \\
Jump Rope & 1.53 \\
Table Tennis & 1.28 \\
Football & 0.94 \\
Yoga & 0.77 \\
Aerobics & 0.71 \\
Volleyball & 0.7 \\
Tai Chi & 0.5 \\
Tennis & 0.19 \\
Shuttlecock & 0.06 \\
Hula Hoop &
\end{tabular}

Table 12 shows the average composite score for the ranked question "perceived benefits of exercise (only three items can be chosen)". The data shows that the main perceived benefits of physical activity for current university students are increasing energy, mood, emotional relief (9.91), improving body shape (3.6) and increasing athletic ability (3.21).

Table 12: Average composite score for the ranking question

"Perceived benefits of exercise (only three items can be chosen)"

\begin{tabular}{cc}
\hline Exercise Benefits & Average composite score \\
\hline Feel energised, happy and relieved & 9.91 \\
Improved body shape & 3.6 \\
Increased athletic ability & 3.21 \\
Good for restful sleep & 2.62 \\
Strengthened respiratory capacity and & 1.91 \\
increased lung capacity & \\
Improved cardiovascular system and & 1.77 \\
improved blood pressure & 1.62 \\
Promote friendship and socialization & 1.33 \\
Quality of will is enhanced & 1.31 \\
Relieves pain in parts of the body & 0.79 \\
Immunity boost & 0.55 \\
Speeds up digestion in the & 0.21 \\
gastrointestinal tract & Other
\end{tabular}

Table 13 shows the average composite score for the ranked question "Help received when participating in physical activity (only three items can be chosen)". The data shows that currently university students mainly receive help from teachers and schools (4.19) and mobile apps such as "keep" (3.74) when participating in physical activity. Relatives $(0.53)$ and social sports instructors (0.38) were less helpful and underutilised.

Table 13: Average composite score for the ranking question "Help received while participating in physical activity (only three items can be chosen)"

\begin{tabular}{cc}
\hline Help received & Average composite score \\
\hline Teachers and Schools & 4.19 \\
mobile apps such as keep & 3.74 \\
TV, Internet, etc. & 1.94 \\
Guidance help from loved ones & 0.53 \\
Social Sports Instructors and & 0.38 \\
Volunteers & 0.3 \\
Other &
\end{tabular}

Table 14 shows the average composite score for the ranked question "Barriers to exercise (only three items can be chosen)". The data shows that currently university students' participation in physical activity is mainly limited by the lack of leisure time (4.57), lack of willpower (4.43) and lack of company (2.59).

Table 14: Average composite score for the ranking question

"Obstacles to exercise (only three items can be chosen)"

\begin{tabular}{cc}
\hline Obstacles & Average overall score \\
\hline Little free time & 4.57 \\
Lack of willpower & 4.43 \\
No company & 2.59 \\
Little space available for fitness & 2.2 \\
equipment around you & \\
Less motor knowledge and skills & 1.33 \\
acquired & 1.17 \\
Don't like sports & 0.96 \\
Physical injury or illness unsuitable & 0.14 \\
for sport &
\end{tabular}

3.3.2 Comparison of physical activity among university students of different genders

The results of the independent samples t-test analysis comparing the differences between male and female students' exercise showed that there were extremely significant differences between male and female students in the exercise intensity and physical activity level (total score) dimensions $(\mathrm{p}<0.001)$ and very significant differences in the exercise time and exercise frequency dimensions $(\mathrm{p}<0.01)$, with male students being significantly more likely than female students in the exercise intensity, exercise time, exercise frequency and physical activity level (total score) dimensions. These dimensions were significantly higher for boys than for girls, as shown in Table 15.

Table 15: Results of independent samples t-test for physical activity of male and female students

\begin{tabular}{|c|c|c|c|c|c|c|c|}
\hline & Gender & $\mathrm{N}$ & Mean & Std. Deviation & $\mathrm{t}$ & Sig (2-tailed) & Cohen's d \\
\hline \multirow{2}{*}{ Exercise intensity } & Boys & 102 & 40.020 & 31.160 & \multirow{2}{*}{4.527} & \multirow{2}{*}{0.000} & \multirow{2}{*}{0.604} \\
\hline & Girls & 119 & 23.513 & 22.897 & & & \\
\hline \multirow{2}{*}{ Exercise time } & Boys & 102 & 3.059 & 1.448 & \multirow{2}{*}{3.783} & \multirow{2}{*}{0.000} & \multirow{2}{*}{0.506} \\
\hline & Girls & 119 & 2.387 & 1.194 & & & \\
\hline \multirow{2}{*}{ Number of workouts } & Boys & 102 & 2.951 & 1.155 & \multirow{2}{*}{2.806} & \multirow{2}{*}{0.005} & \multirow{2}{*}{0.377} \\
\hline & Girls & 119 & 2.487 & 1.301 & & & \\
\hline \multirow{2}{*}{ Level of physical activity (total points) } & Boys & 102 & 3.510 & 0.992 & \multirow{2}{*}{3.086} & \multirow{2}{*}{0.002} & \multirow{2}{*}{0.415} \\
\hline & Girls & 119 & 3.076 & 1.098 & & & \\
\hline
\end{tabular}

3.3.3 Comparison of physical exercise among university students of different grades

A one-way ANOVA comparing the differences between the four types shows that there is no variability in the intensity of exercise, frequency of exercise and physical activity level (total score) dimensions between the different grades, and there is very significant variability in the duration of exercise dimension, as shown in Table 16. 
Table 16: Comparison of differences in physical activity among university students in different grades

\begin{tabular}{|c|c|c|c|c|c|c|}
\hline & $\begin{array}{c}\text { First year students } \\
(\mathrm{n}=60) \\
(\text { Mean, SD) }\end{array}$ & $\begin{array}{c}\text { Second year students } \\
(\mathrm{n}=73) \\
(\text { Mean, SD) }\end{array}$ & $\begin{array}{c}\text { Third year students } \\
(\mathrm{n}=52) \\
(\text { Mean, SD) }\end{array}$ & $\begin{array}{l}\text { Masters and } \mathrm{PhD} \\
\text { students }(\mathrm{n}=24) \\
(\text { Mean, } \mathrm{SD})\end{array}$ & $\mathrm{F}$ & $\mathrm{p}$ \\
\hline Exercise intensity & $(2.800,1.447)$ & $(2.479,1.226)$ & $(2.615,1.301)$ & $(3.125,1.569)$ & 1.599 & 0.191 \\
\hline Exercise time & $(3.000,1.353)$ & $(2.301,1.151)$ & $(2.692,1.229)$ & $(3.042,1.083)$ & 4.391 & $0.005^{* * *}$ \\
\hline Number of workouts & $(3.450,1.141)$ & $(3.192,0.995)$ & $(3.250,1.153)$ & $(3.250,1.032)$ & 0.671 & 0.571 \\
\hline $\begin{array}{l}\text { Level of physical activity (total } \\
\text { points) }\end{array}$ & $(36.267,30.319)$ & $(25.507,26.234)$ & $(29.923,27.648)$ & $(36.208,29.671)$ & 1.919 & 0.128 \\
\hline
\end{tabular}

Note: 米米 $\mathrm{p}<0.01$.

Further multiple comparisons revealed that on the exercise time dimension, second year students were significantly lower than first year students $(\mathrm{p}<0.01)$ and second year students were significantly lower than MSc PhD students $(\mathrm{p}<0.05)$, indicating that second year students spent less time exercising relative to first year and $\mathrm{MSc} \mathrm{PhD}$ students, as shown in Table 17.

Table 17: Multiple comparisons of physical activity time among students in different grades

\begin{tabular}{|c|c|c|c|c|c|}
\hline $\begin{array}{l}\text { Dependent } \\
\text { variable }\end{array}$ & $\begin{array}{l}\text { (I) } \\
\text { Grade }\end{array}$ & (J) Grade & $\begin{array}{l}\text { Mean } \\
\text { Difference } \\
(\mathrm{I}-\mathrm{J})\end{array}$ & $\begin{array}{l}\text { Std. } \\
\text { Error }\end{array}$ & Sig \\
\hline \multirow{3}{*}{$\begin{array}{l}\text { Exercise } \\
\text { time }\end{array}$} & \multirow{3}{*}{$\begin{array}{l}\text { Sopho } \\
\text { more }\end{array}$} & Freshman year & -0.699 ** & 0.213 & $\begin{array}{l}0.0 \\
01\end{array}$ \\
\hline & & Third Year & -0.391 & 0.222 & $\begin{array}{l}0.0 \\
80\end{array}$ \\
\hline & & $\begin{array}{l}\text { Masters and } \\
\text { PhD students }\end{array}$ & $-0.740^{*}$ & 0.288 & $\begin{array}{l}0.0 \\
11\end{array}$ \\
\hline
\end{tabular}

Note: ${ }^{*} \mathrm{p}<0.05$, ${ }^{*}$ p $\mathrm{p}<0.01$, ***** $\mathrm{p}<0.001$.

\subsection{Analysis of the Effect of Physical Activity on Stress Status Among University Students}

In this study, the four dimensions of personal annoyance, study annoyance, negative learning events, and negative life events were regressed as independent variables against physical activity as the dependent variable in order to reveal the contribution of each influencing factor to physical activity and the degree of importance.

3.4.1 Analysis of the correlation between the four dimensions and physical activity

The premise of the regression analysis was to determine that there was a correlation between the four dimensions and physical activity. According to the analysis, a highly significant negative correlation $(\mathrm{p}<0.01)$ exists between physical exercise and the personal annoyance and learning annoyance dimensions, as shown in Table 18, indicating that the more physical exercise there is, the less stress there is in terms of personal annoyance and learning annoyance; and the less physical exercise there is, instead the more stress there is perceived in terms of personal annoyance and learning annoyance.

Table 18: Correlation analysis

\begin{tabular}{lcccc}
\hline & $\begin{array}{c}\text { Personal } \\
\text { Annoyance }\end{array}$ & $\begin{array}{c}\text { Study } \\
\text { Annoyanc } \\
\mathrm{e}\end{array}$ & $\begin{array}{c}\text { Negative } \\
\text { Learning } \\
\text { Events }\end{array}$ & $\begin{array}{c}\text { Negative } \\
\text { Life Events }\end{array}$ \\
\hline $\begin{array}{l}\text { Physical } \\
\text { Exercise }\end{array}$ & $-0.222^{* * *}$ & $-0.236^{* *}$ & -0.121 & -0.126 \\
\hline Note: ${ }^{* *} \mathrm{p}<0.01$. & & &
\end{tabular}

3.4.2 Multiple regression analysis of the four dimensions and learning engagement

Using personal annoyance and academic annoyance as independent variables and physical activity as dependent variables, the results of the analysis are shown in Table 19. According to the results, $\mathrm{F}=6.731, \mathrm{p}<0.01, \mathrm{R}=02.061$, the model was significant overall $(\mathrm{p}<0.01)$ and $6.1 \%$ of the variance in physical activity could be explained by the variance in the two independent variables of personal annoyance and learning annoyance. Of the two variables, personal annoyance $(\beta=-0.11, \mathrm{t}=-1.136)$, and learning annoyance $(\beta=-0.157, \mathrm{t}=-1.616)$ predicted the variance.

Table 19: Coefficients

\begin{tabular}{cccccc}
\hline & \multicolumn{2}{c}{$\begin{array}{c}\text { Unstandardized } \\
\text { Coefficients }\end{array}$} & $\begin{array}{c}\text { Standardized } \\
\text { Coefficients }\end{array}$ & & \multirow{2}{*}{ S } \\
\cline { 2 - 4 } & $\mathrm{B}$ & $\begin{array}{c}\text { Std. } \\
\text { Error }\end{array}$ & Beta & & \\
\hline (Constant) & 41.063 & 3.392 & & 12.105 & 0 \\
$\begin{array}{c}\text { Personal } \\
\text { annoyance } \\
\text { Study }\end{array}$ & -3.917 & 3.45 & -0.11 & -1.136 & 0.257 \\
annoyance & -6.04 & 3.738 & -0.157 & -1.616 & 0.018 \\
\hline
\end{tabular}

\section{Discussion}

Stress has an important impact on the psychological health and development of university students. This study found that students in some of the universities in Beijing surveyed are generally stressed, with academic annoyances causing the most stress, which is more in line with relevant studies by previous scholars[17], followed by personal annoyances, negative life events and negative academic events, with students in a high stress state accounting for $17.6 \%$ of the total. Therefore, the current mental health of university students should first focus on their academic stress, and teach students how to better cope with academic stress in mental health classes or extra-curricular lectures. Tutors, class teachers and other teachers should increase their understanding of students' academic stress in their daily study life, and provide guidance according to their needs. The results of the survey show that academic students have significantly higher scores than sports students in the dimensions of academic annoyance, personal annoyance and total stress, which may be related to the pressure of coursework, professional development and employment prospects. Therefore, further planning and design of professional courses for different types of students should be undertaken. At the same time, schools and relevant departments should conduct institutional studies to alleviate the academic pressure of university students and break the current vicious competition in learning such as "involution".

Male students scored significantly higher than female students on personal annoyance, negative learning events, and total stress scores, which may be related to gender role stereotypes [18]. For male students, due to the gender role stereotype that male should be stronger than female and play more of a role in some aspects, male are generally reluctant to talk to others about their feelings and even more reluctant to seek 
psychotherapy [19]. And male may have higher expectations of themselves, be more motivated to achieve and be more competitive, which can lead to greater stress [20]. Therefore, when providing mental health education for university students, it is important to focus on stress for male and female students separately to minimise the negative effects of gender role stereotyping.

The data shows that currently university students have a certain degree of physical exercise on a daily basis, but the intensity, duration and frequency of exercise need to be improved. "Realising one's hobbies" is at the top of the list of college students' exercise purposes; while "weak personal willpower" accounts for a significant proportion of the hindering factors for exercise. This is partly due to the students' weak will to exercise and poor initiative, which can be attributed to their lack of personal interest in sport. This reveals the need to develop children's interest in sport from an early age, which requires parents and schools to work together to create a synergy. Parents should play a full role in guiding and accompanying their children from an early age to take up sports and acquire their favourite sporting skills, taking into account the actual situation and their children's preferences. This helps to expand the child's after-school life and also provides adequate physical exercise, laying a good foundation for lifelong sport. At the same time, schools should develop a wide range of physical activities. Schools should make every effort to be diverse and interesting in their physical activities. They should insist on holding at least one whole-school type sports day in each school year, and also conduct regular sports games, fun games, and create sports clubs to break down the hindrances to exercise such as "no company" to a certain extent. Schools should revitalise their thinking, be creative and continue to promote innovation in school sports reform, establishing it as an institution that evokes students' interest in a variety of forms and attracts their active participation so that they feel the multiple benefits of sport.

The findings show that students' personal annoyances and academic annoyances can predict physical activity to a certain extent. As physical activity has a moderating effect on stress [21], some students use it as a way to reduce stress. The results of the survey show that second-year university students have significantly higher personal annoyance, academic annoyance and overall scores than students in other years, which may be partly due to the fact that second-year university students spend less time exercising than students in other years. This may also be due in part to the fact that art students are significantly more physically active than their academic counterparts, with physical activity playing a role in regulating stress. Therefore, when conducting mental health education in schools, the moderating effect of physical exercise on mental health should be taught to students so that they can relieve their psychological stress through physical exercise.

\section{Conclusion}

This study investigated the current stress situation (including the four dimensions of personal annoyance, study annoyance, negative learning events and negative life events) and physical exercise among university students through a questionnaire method, and also compared the differences in the four dimensions of stress situation among students of different genders, subject disciplines and different grades, which has implications for further promoting university students' mental health and physical exercise. Further research is needed to expand the sample size and continue to explore the factors that influence stress and physical activity among university students.

\section{Acknowledgments}

We would like to express our gratitude to those who have helped with this study. We hope that all young people can love sports and have a strong body.

\section{Authors' Contributions}

Li Moyan contributed to the analysis, and drafted the manuscript. Deng Pengyu contributed to the release of the questionnaire and part of the writing. All authors have read and agreed to the published version of the manuscript.

\section{Availability of Data and Materials}

The data are not available due to privacy and ethical restrictions.

\section{Ethics Approval and Consent to Participate}

Research meets ethical and moral standards

\section{Competing Interests}

The authors declare no conflict of interest.

\section{References}

[1] World Health Organization. (1958). Preamble to the Constitution. In: The First Ten Years of the World Health Organization. Geneva: The Organization, 459.

[2] McCarrick, P. M. (1992). A Right to Health Care. Kennedy Institute of Ethics Journal, 2(4), 389-405.

[3] Anderson, R.. (2004). Stress and mental health. Journal of the Royal Society for the Promotion of Health, 124(3), 112.

[4] Butler, M., Warfa, N., Khatib, Y., \& Bhui, K.. (2015). Migration and common mental disorder: an improvement in mental health over time?. International Review of Psychiatry, 27(1), 51-63.

[5] Pulido-Martos, M., Lopez-Zafra, E., F Estévez-López, \& Augusto-Landa, J. M.. (2016). The moderator role of perceived emotional intelligence in the relationship between sources of stress and mental health in teachers. Span J Psychol, 19.

[6] Shi Rong-Hua. (1998). Dictionary of social psychology. Chengdu: Sichuan People's Publishing House, 118.(In Chinese)

[7] Kulakow, S., Raufelder, D., \& Hoferichter, F.. (2021). School-related pressure and parental support as predictors of change in student stress levels from early to middle adolescence. Journal of Adolescence, 87, 38-51. 
[8] Higgins, \& Kristen. (2019). Stress in college students: worse than the "freshman 15?". Steeplechase: An ORCA Student Journal, 3(1), 5-5.

[9] Bovier P A, Perneger C T V. (2004). Perceived stress, internal resources, and social support as determinants of mental health among young adults. Quality of Life Research, 13(1), 161-170.

[10] Ruthig, J. C., Haynes, T. L., Stupnisky, R. H., \& Perry, R. P.. (2009). Perceived academic control: mediating the effects of optimism and social support on college students' psychological health. Social Psychology of Education, 12(2), 233-249.

[11] Fernandes, E. V., Venancio, E. J., Estanislau, C., Ramos, S., \& Machado, F. A.. (2021). Impact of interaction between chronic variable stress and moderate intensity physical exercise on antibody production in wistar rats. Indian Journal of Experimental Biology, 58, 406-414.

[12] Muhsen, T.. (2020). The impact of physical activity and sport on mental health.

[13] Popov, S., Soki, J., \& Duan, S.. (2021). Activity matters: physical exercise and stress coping during the 2020 covid-19 state of emergency. Psihologija.

[14] Benson, \& Kaylani. (2017). The Effects of Exercise on Mental Health: A Research Review.

[15] Zhang, G., Yue, Q., Mei, C., \& University, B. S.. (2017). The relationship between physical activities and external problem behaviors of adolescents: the mediating effect of self-esteem. Chinese Journal of Sports Medicine.

[16] Li Hong, Mei Jinrong.. (2002). Development of a stress scale for college students[J]. Applied Psychology, 01, 27-32.(In Chinese)

[17] Liu, Chen-Ling. A Study on Daily Life Stress, Social Support and its Correlation among College Students[D]. Huazhong Normal University, 2002.(In Chinese)

[18] Kai, X. U.. (2016). Impact of gender role conflict on psychological health development among middle school students. Chinese Journal of School Health.

[19] Paul D. Cleary, David Mechanic (1983). Sex Differences in Psychological Distress among Married People. 24(2): 111-121. 